\title{
PERANAN BLENDED LEARNING BERBANTUAN GOOGLE CLASSROOM PADA MATERI HUKUM NEWTON TERHADAP KETERAMPILAN BERPIKIR KREATIF
}

\author{
Musdar M ${ }^{1, a}$, Nurlina ${ }^{2, b}$, Muh Ilham Asy'ari ${ }^{3, b}$ \\ 1,2,3 Universitas Sulawesi Barat \\ e-mail: ${ }^{a}$ musdar@unsulbar.ac.id, ${ }^{\text {bnurlina@unsulbar.ac.id, }}$, ilhamashari24@gmail.com
}

\begin{abstract}
Abstrak
Tujuan penelitian ini adalah untuk mengetahui perbedaan keterampilan berpikir kreatif peserta didik kelas $\mathrm{X}$ IPA di SMA Negeri 1 Campalagian yang diajar menggunakan blended learning berbantuan google classroom dan yang diajar tanpa menggunakan blended learning berbantuan google classroom. Metode penelitian yang digunakan adalah quasi eksperimen dengan desain nonequivalent control group design. Adapun sampel penelitian yang digunakan sebanyak 74 peserta didik yang dibagi menjadi dua kelompok kelas, yaitu kelas eksperimen dan kelas kontrol. Teknik pengambilan sampel menggunakan purposive sampling. Instrumen yang digunakan adalah tes berupa essay, rpp dan lembar keterlaksanaan rpp. Sebelum instrumen tes digunakan, instrumen ini telah diuji validitasnya. Melalui validasi 20 soal diuji untuk memperoleh soal yang valid, kemudian dipilih menjadi 10 soal yang digunakan dalam penelitian dan soal tersebut sudah mewakili setiap indikator. Hasil dari tes tersebut dilakukan uji statistik menggunakan uji t yang menunjukkan bahwa nilai signifikansi (2-tailed) $<0,05$ maka $H_{0}$ ditolak dan $H_{1}$ diterima. Dengan demikian, dapat disimpulkan bahwa terdapat perbedaan blended learning berbantuan google classroom pada materi hukum Newton terhadap keterampilan berpikir kreatif peserta didik.
\end{abstract}

Kata kunci: blended learning, keterampilan berpikir kreatif

\section{THE ROLE OF GOOGLE CLASSROOM ASSISTANT BLENDED LEARNING IN NEWTON'S LAW MATERIALS ON CREATIVE THINKING SKILLS}

\begin{abstract}
The purpose of this study was to determine the differences in creative thinking skills of students in class $X$ science at SMA Negeri 1 Campalagian who were taught using blended learning assisted by Google Classroom and those taught without using blended learning assisted by Google Classroom. The research method used is a quasi-experimental design with a nonequivalent control group design. The research sample used was 74 students who were divided into two class groups, namely the experimental class and the control class. The sampling technique used purposive sampling. The instruments used are tests in the form of essays, lesson plans and rpp implementation sheets. Before the test instrument is used, this instrument has been tested for validity. Through the validation of 20 questions were tested to obtain valid questions, then 10 questions were selected to be used in the study and the questions represented each indicator. The results of the test were statistically tested using the t-test which showed that the significance value $(2$-tailed $)<0.05$, then $H_{0}$ was rejected and $H_{1}$ was accepted. Thus, it can be concluded that there are differences in blended learning assisted by Google Classroom in Newton's law material on students' creative thinking skills.
\end{abstract}

Keywords: blended learning, creative thinking skills 


\section{PENDAHULUAN}

Pendidikan merupakan salah satu pilar utama dalam mengantisipasi masa depan, pendidikan selalu diorientasikan pada penyiapan peserta didik untuk berperan dan berkontribusi aktif di masa yang akan datang terutama bagi pembangunan bangsa dan negara. Kemajuan suatu bangsa bergantung kepada cara bangsa tersebut mengenali, menghargai dan memanfaatkan Sumber Daya Manusia (SDM), maka hal ini berkaitan erat dengan kualitas pendidikan yang diberikan kepada anggota masyarakatnya yaitu peserta didik. Pendidikan adalah suatu usaha sadar dan terencana untuk mewujudkan suasana dan proses pembelajaran agar peserta didik secara aktif mengembangkan potensi dirinya untuk memiliki kekuatan spiritual keagamaan, pengendalian diri, kepribadian, kecerdasan, akhlak mulia, serta keterampilan yang diperlukan dirinya, masyarakat, bangsa dan negara [1].

Media pembelajaran merupakan sarana dalam pembelajaran yang digunakan untuk menyampaikan informasi kepada peserta didik. Selain itu, media pembelajaran dapat membantu guru dalam menyampaikan materi yang diajarkan dan membantu peserta didik dalam memahami materi pembelajaran. Media pembelajaran digunakan sebagai salah satu solusi untuk mengatasi masalah pembelajaran. Inovasi media pembelajaran saat ini salah satunya dengan menggunakan internet sebagai sumber belajar. Internet dapat diartikan sebagai media yang mampu memfasilitasi guru serta peserta didik dalam proses pembelajaran [3]. Adanya internet memberikan manfaat yang banyak dalam pembelajaran di sekolah, dimana peserta didik mampu memenuhi kebutuhan akan ilmu pengetahuan yang diinginkan. Perkembangan teknologi dan informasi mampu memberikan fasilitas yang memudahkan proses pembelajaran di sekolah.

Google Classroom merupakan platform yang bisa menciptakan proses pembelajaran dalam ruang kelas dalam dunia maya [2]. Selain itu, Google Classroom atau ruang kelas google merupakan suatu serambi pembelajaran campuran untuk ruang lingkup pendidikan yang dapat memudahkan pengajar dalam membuat, membagikan dan menggolongkan setiap penugasan tanpa kertas [4].

Keterampilan berpikir kreatif adalah kemampuan mengembangkan ide-ide atau gagasan yang tak biasa serta pemikiran yang baru. Kemampuan berpikir kreatif sangat penting dimiliki oleh setiap individu, terlebih di era global berbasis pengetahuan dan juga teknologi [5]. Sehingga, peserta didik dapat mengembangkan daya pikir yang mencakup pemikiran dan wawasan yang lebih luas.

Berdasarkan hasil observasi pada bulan Mei 2021 di SMA Negeri 1 Campalagian, kegiatan dalam proses pembelajaran yang berpusat pada guru mengakibatkan rendahnya pemahaman peserta didik yang dibuktikan dengan perolehan nilai ulangan yang kurang maksimal, sebagian besar di atas $50 \%$ peserta didik memperoleh nilai dibawah kriteria ketuntasan (KKM). Pemahaman peserta didik di dalam kelas kurang maksimal, apalagi dengan adanya pandemi yang mengharuskan peserta didik belajar virtual. Selain itu, rendahnya kemampuan keterampilan berpikir kreatif yang ditunjukkan peserta didik pada proses pembelajaran yang kurang berkontribusi aktif baik dalam bertanya, menjawab pertanyaan, maupun mengemukakan dan mengembangkan ide serta gagasannya. Sehingga penggunaan pembelajaran blended learning yang mengkombinasikan pembelajaran langsung dengan pembelajaran virtual dalam proses pembelajaran diharapkan dapat meningkatkan pemahaman peserta didik sekaligus kemampuan berpikir kreatifnya yang dipandu dengan Google Classroom agar tercipta pembelajaran yang lebih efektif dan efisien sehingga membuat peserta didik lebih aktif dalam proses pembelajaran.

Blended learning memiliki kelebihan yang sangat potensial sebagai sumber belajar bagi peserta didik yang tidak memiliki cukup waktu untuk belajar dan juga memfasilitasi bahan belajar tambahan yang digunakan agar dapat mempermudah pemahaman materi pembelajaran. Blended learning dapat digunakan sebagai salah satu variasi dalam proses pembelajaran yang dapat membantu peserta didik lebih berpartisipasi aktif dan juga mampu meningkatkan kemampuan berpikir kreatif. 
Penelitian yang relevan menyatakan bahwa terdapat pengaruh pembelajaran blended learning berbantukan Google Classroom terhadap kemampuan berpikir kreatif dan kemandirian belajar peserta didik [5].

\section{METODE}

\section{Jenis Penelitian}

Penelitian ini adalah penelitian kuantitatif dengan menggunakan metode quasi-experiment yang menggunakan desain Nonequivalent Control Group Design. Desain ini hampir sama dengan pretest-posttest control group design, hanya pada desain ini kelompok eksperimen maupun kelompok kontrol tidak dipilih secara random. Sebelum diberikan perlakuan, kelompok eksperimen dan kelompok kontrol diberikan tes awal (pretest) dengan maksud untuk mengetahui keadaan kelompok sebelum perlakuan.

\section{Waktu dan Tempat Penelitian}

Penelitian ini dilaksanakan di SMA Negeri 1 Campalagian yang bertempat di Lapeo Jalan Poros Majene, Kecamatan Campalagian, Kabupaten Polewali Mandar, Provinsi Sulawesi Barat pada tanggal September-Oktober 2021.

\section{Subjek Penelitian}

Populasi dalam penelitian ini adalah seluruh peserta didik kelas X IPA di SMA Negeri 1 Campalagian tahun ajaran 2021/2022 yang terdiri dari 5 kelas (X IPA 1-X IPA 5) dengan jumlah 184 orang.

Sampel pada penelitian ini menggunakan dua kelompok kelas yaitu kelas X IPA 1 sebagai kelas eksperimen dan kelas X IPA 2 sebagai kelas kontrol. Adapun teknik pengambilan sampel dalam penelitian ini menggunakan purposive sampling. Purposive sampling adalah teknik pengambilan sampel dengan pertimbangan tertentu untuk menghasilkan sampel yang secara logis dapat dianggap mewakili populasi.

\section{Prosedur}

Tahap Persiapan: Mengadakan observasi ke sekolah dan berkonsultasi dengan guru bidang studi fisika kelas $\mathrm{X}$ mengenai keadaan peserta didik, hasil belajar fisika peserta didik, model pembelajaran, materi pelajaran yang akan diteliti serta waktu penelitian. Membuat perangkat pembelajaran dan menyiapkan pembelajaran yang sesuai dengan pembelajaran blended learning. Menyusun instrumen tes terkait kemampuan keterampilan berpikir kreatif peserta didik dalam materi hukum Newton.

Tahap Pelaksanaan: Menentukan kelas kontrol dan kelas eksperimen. Memberikan tes awal (pretest) dalam pembelajaran sebelum diterapkan blended learning berbantuan Google Classroom. Melaksanakan proses pembelajaran dengan menerapkan blended learning berbantuan Google Classroom pada kelas eksperimen.

Tahap Akhir: Setelah seluruh rangkaian pengajaran dilaksanakan maka dilakukan tes akhir (posttest) pada kedua kelas. Peneliti akan memberikan tes akhir (posttest) setelah diterapkan blended learning berbantuan Google Classroom pada kelas yang dijadikan sampel dalam penelitian.

\section{Instrumen Penelitian}

Untuk mendapatkan data mengenai variabel yang diteliti dalam penelitian ini digunakan instrumen, berupa tes keterampilan berpikir kreatif dalam bentuk tes essay yang akan diuji coba sebelum digunakan dalam penelitian untuk mengetahui validitas dan reliabilitas tes tersebut.

Sebelum instrumen tes keterampilan berpikir kreatif digunakan dalam penelitian, terlebih dahulu dikonsultasikan ke dosen pembimbing. Setelah instrumen selesai divalidasi oleh dosen pembimbing dan telah direvisi oleh peneliti, maka selanjutnya dilakukan uji instrumen agar diketahui apakah isi tersebut layak untuk digunakan atau dengan kata lain tes tersebut valid dan dapat dipercaya.

Instrumen untuk tes berupa soal uji coba dan soal pretest-posttest. Soal uji coba terdiri dari 20 soal essay. Soal tersebut kemudian diuji untuk memperoleh soal yang valid dan kemudian dipilih menjadi 10 soal yang digunakan untuk soal pretest dan posttest.

\section{Teknik Analisis Data}

Data yang dianalisis dari hasil penelitian ini adalah hasil tes kemampuan keterampilan berpikir kreatif peserta didik melalui pretest dan posttest. Data tersebut dianalisis dengan menggunakan teknik analisis deskriptif dan analisis inferensial. 


\section{Analisis Deskriptif}

Analisis ini dimaksudkan untuk memberikan gambaran mengenai persentase pencapaian kemampuan keterampilan berpikir kreatif peserta didik dengan menerapkan pembelajaran blended learning berbantuan Google Classroom.

Rumus yang digunakan dalam analisis deskriptif untuk penelitian ini adalah:

Menghitung rata-rata $(\underline{X})[8]$.

$\underline{X}=\frac{\Sigma f_{i} x_{i}}{n}$

Standar deviasi berfungsi memperlihatkan pola sebaran data dan variansi sebaran antar data [8].

$\mathrm{S}=\frac{\sqrt{n \Sigma f_{i} x_{i}^{2}-\left(\Sigma f_{i} x_{i}\right)^{2}}}{n(n-1)}$

Pengubahan skor hasil kemampuan keterampilan berpikir kreatif ke bentuk nilai persentase dihitung dengan menggunakan rumus sebagai berikut [8]:

Skor $=\frac{\text { jumlah skor }}{\text { skor maksimal }} \times 100 \%$

Tabel 1. Kategori Kemampuan Keterampilan Berpikir Kreatif

\begin{tabular}{ll}
\hline Interval Nilai & Kategori \\
\hline $81 \leq x$ & Sangat Tinggi \\
\hline $61 \leq x \leq 80$ & Tinggi \\
\hline $41 \leq x \leq 60$ & Sedang \\
\hline $21 \leq x \leq 40$ & Rendah \\
\hline $\mathrm{x} \leq 20$ & Sangat Rendah \\
\hline
\end{tabular}

\section{Analisis Inferensial}

Statistik inferensial digunakan untuk menguji hipotesis penelitian. Sebelum dilakukan pengujian hipotesis, terlebih dahulu dilakukan pengujian dasar-dasar analisis yaitu uji normalitas yang dirumuskan sebagai berikut:

\section{Uji Normalitas Data}

Pengujian normalitas yang digunakan pada penelitian ini adalah dengan metode Chi-Kuadrat yang bertujuan untuk mengetahui data yang diteliti, apakah data yang diperoleh dari responden berdistribusi normal atau tidak dengan menggunakan rumus sebagai berikut [6]:

$x^{2}=\sum_{i=1}^{k} \frac{\left(f_{o}-f_{h}\right)^{2}}{f_{h}}$
Keterangan:

$x^{2} \quad$ :Chi-Kuadrat

$k \quad$ :banyaknya kelas interval

$f_{o} \quad$ :frekuensi yang diobservasi

$f_{h} \quad$ :frekuensi yang diharapkan

Kriteria pengujian normalitas dengan $\alpha=0,05$

Jika $x_{\text {hitung }}^{2} \geq x_{\text {tabel }}^{2}$, artinya distribusi data tidak normal

Jika $x_{\text {hitung }}^{2}<x_{\text {tabel }}^{2}$, artinya distribusi data normal

\section{Uji Hipotesis}

Pengujian hipotesis yang dilakukan adalah uji statistik parametrik yaitu menggunakan uji t. Rumus yang digunakan adalah [7]:

$\mathrm{t}=\frac{M d}{\sqrt{\frac{\Sigma X^{2} d}{N(N-1)}}}$

Hipotesis penelitian sebagai berikut:

$$
\begin{aligned}
& H_{0}: \mu_{0}=\mu_{1} \\
& H_{1}: \mu_{0} \neq \mu_{1}
\end{aligned}
$$

Keterangan:

$\mu_{1}$ : Rata-rata populasi nilai kemampuan keterampilan berpikir kreatif yang diperoleh peserta didik setelah menggunakan pembelajaran blended learning.

$\mu_{0}$ : Rata-rata populasi nilai kemampuan keterampilan berpikir kreatif yang diperoleh peserta didik sebelum menggunakan pembelajaran blended learning.

$H_{0}$ : Tidak terdapat perbedaan kemampuan keterampilan berpikir kreatif setelah diajar dengan menggunakan pembelajaran blended learning.

$H_{1}$ : Terdapat perbedaan kemampuan keterampilan berpikir kreatif setelah diajar dengan menggunakan pembelajaran blended learning.

Kriteria Pengujian Hipotesis:

Jika $t_{\text {hitung }}>t_{\text {tabel }}$, maka tolak $H_{0}$ dan terima $H_{1}$, berarti terdapat perbedaan kemampuan keterampilan berpikir kreatif peserta didik setelah diajar menggunakan blended learning berbantuan Google Classroom pada materi hukum Newton.

Jika $t_{\text {hitung }}<t_{\text {tabel }}$, maka tolak $H_{1}$ dan terima $H_{0}$, berarti tidak terdapat perbedaan kemampuan 
keterampilan berpikir kreatif peserta didik setelah diajar menggunakan blended learning berbantuan Google Classroom pada materi hukum Newton.

\section{HASIL DAN DISKUSI}

Penelitian ini dilaksanakan sebanyak 5 kali pertemuan pada kelompok kelas eksperimen maupun kelas kontrol. Penelitian ini memberikan perlakuan yang berbeda kepada kedua kelompok kelas tersebut. Kelas eksperimen belajar menggunakan pembelajaran blended learning berbantuan google classroom, sedangkan kelas kontrol belajar menggunakan model pembelajaran langsung.

Data yang diperoleh dalam penelitian ini adalah data yang terkumpul dari tes yang diberikan kepada peserta didik di SMA Negeri 1 Campalagian berupa pretest dan posttest yang diberikan pada kelas eksperimen dan kelas kontrol. Pretest diberikan sebelum adanya perlakuan untuk mengetahui kemampuan awal peserta didik, sedangkan posttest diberikan setelah perlakuan diberikan dengan menggunakan blended learning berbantuan google classroom. Instrumen yang digunakan pada pretest dan posttest dalam penelitian ini meliputi data hasil belajar peserta didik melalui tes keterampilan berpikir kreatif sebanyak 10 soal essay yang telah divalidasi.

\section{Analisis Deskriptif}

Hasil

pretest dan posttest kelas eksperimen dan kelas kontrol yang terdiri dari 37 peserta didik disajikan dalam tabel berikut:
Tabel 2 Rekapitulasi Distribusi Data Hasil Pretest-Posttest Kelas Eksperimen dan Kelas Kontrol

\begin{tabular}{lllll}
\hline \multirow{2}{*}{ Data } & \multicolumn{2}{l}{ Kelas Eksperimen } & \multicolumn{2}{l}{ Kelas Kontrol } \\
\cline { 2 - 5 } & Pretest & Posttest & Pretest & Posttest \\
\hline $\begin{array}{l}\text { Maksi } \\
\text { mum }\end{array}$ & 92 & 98 & 84 & 90 \\
\hline $\begin{array}{l}\text { Minim } \\
\text { um }\end{array}$ & 34 & 52 & 0 & 0 \\
\hline Mean & 58.38 & 73.73 & 44.22 & 57.46 \\
\hline Median & 54.00 & 74.00 & 44.00 & 58.00 \\
\hline Modus & 54 & 74 & 30 & 60 \\
\hline $\begin{array}{l}\text { Standar } \\
\text { deviasi }\end{array}$ & 15.135 & 9.605 & 15.454 & 13.957 \\
\hline
\end{tabular}

Berdasarkan data Tabel 2, ukuran pemusatan dan penyebaran data hasil pretest untuk kelas eksperimen yaitu: nilai tertinggi 92 dan nilai terendah 34, rata-rata (mean) sebesar 58.38, median sebesar 54.00, modus sebesar 54 dan standar deviasi sebesar 15,135. Sedangkan data hasil posttest nilai tertinggi 98 dan nilai terendah 52, rata-rata (mean) sebesar 73.73, median sebesar 74.00, modus sebesar 74 dan standar deviasi 9,605. Untuk kelompok kontrol diperoleh data hasil pretest yaitu: nilai tertinggi 84 dan nilai terendah 0 , rata-rata (mean) sebesar 44.22, median sebesar 44.00, modus sebesar 30 dan standar deviasi sebesar 15,454. Sedangkan data hasil posttest nilai tertinggi 90 dan nilai terendah 0, rata-rata (mean) sebesar 57.46, median sebesar 58.00, modus sebesar 60 dan standar deviasi 13,957.

Rekapitulasi data pretest kelas eksperimen dan kelas kontrol dapat dilihat pada diagram batang berikut. 


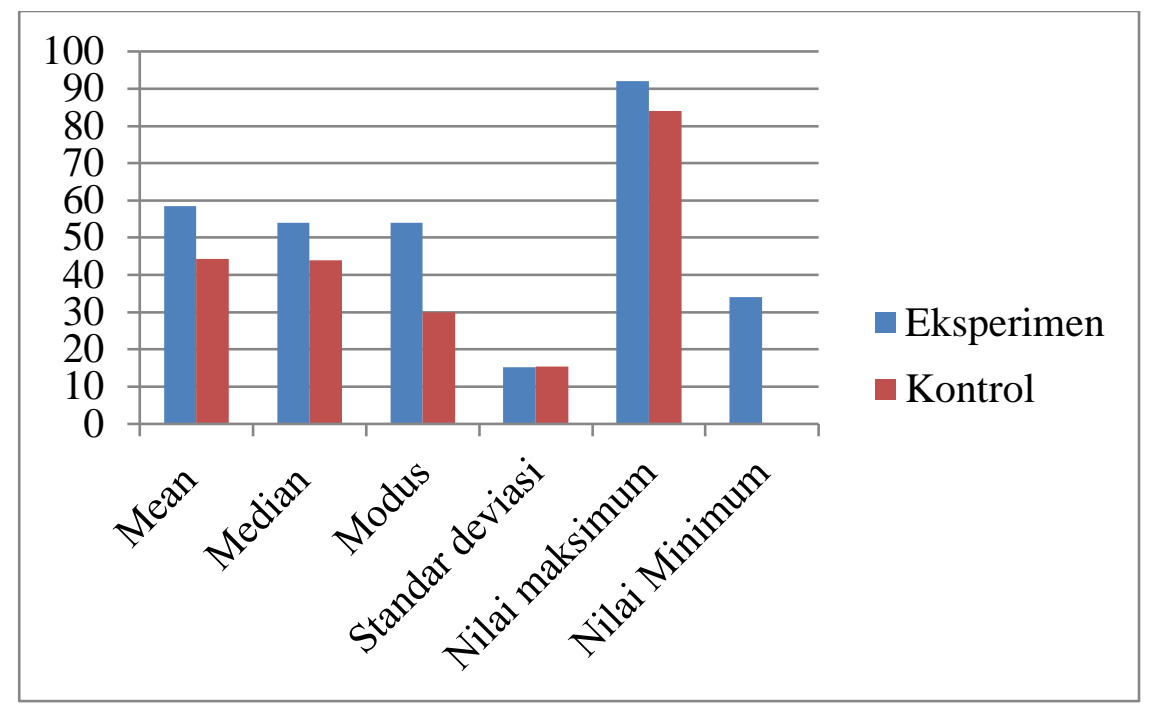

Gambar 1. Histogram Data Hasil Pretest Kelas Eksperimen dan Kelas Kontrol

Adapun rekapitulasi data hasil posttest kelas eksperimen dan kontrol dapat dilihat pada diagram gambar 2.

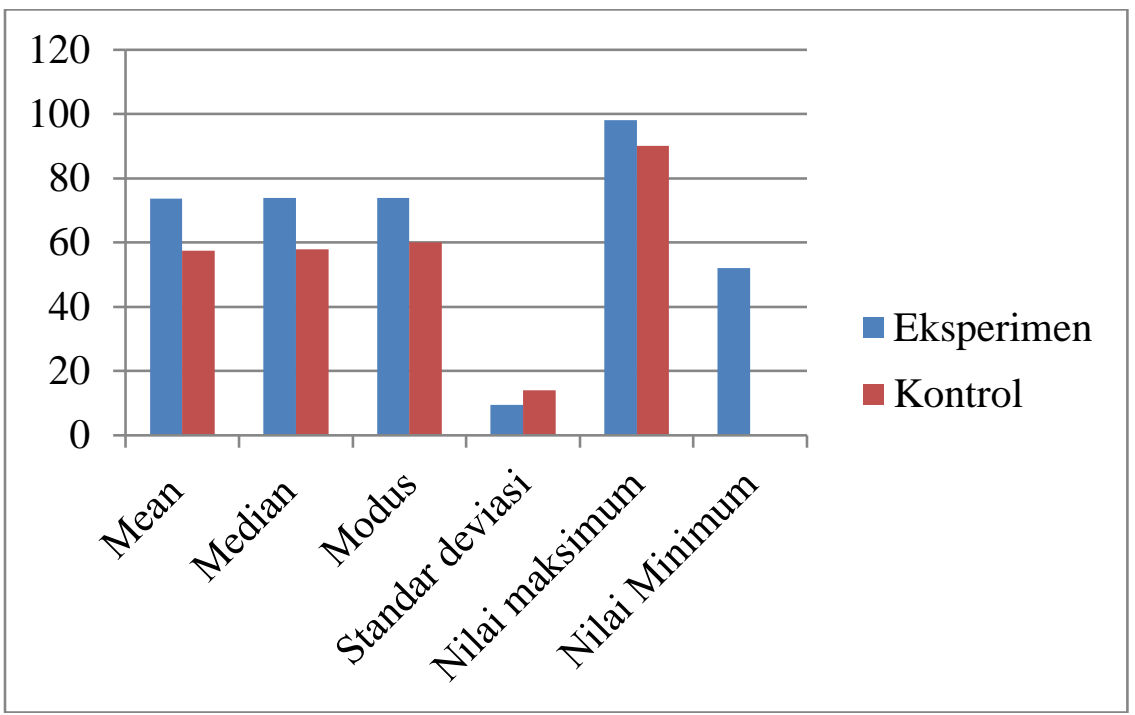

Gambar 2. Histogram Data Hasil Posttest Kelas Eksperimen dan Kelas Kontrol

Analisis Inferensial

\section{Uji Normalitas}

Uji normalitas dilakukan untuk mengetahui apakah sampel yang diteliti berdistribusi normal atau tidak. Adapun kriteria penerimaan bahwa suatu data berdistribusi normal atau tidak dengan menggunakan rumus sebagai berikut:

Jika sig $<0.05$, artinya distribusi data tidak normal

Jika sig $>0.05$, artinya distribusi data normal
Berdasarkan hasil uji normalitas data Pretest-Posttest Kelas Eksperimen dan Kelas Kontrol

Berdasarkan data Tabel 2, dapat disimpulkan bahwa data hasil pretest maupun posttest kedua kelas berdistribusi normal memenuhi kriteria yaitu jika sig $>0.05$, artinya distribusi data normal.

\section{Uji Homogenitas}

Setelah kedua sampel kelas dinyatakan berdistribusi normal, selanjutnya dilakukan pengujian homogenitas. Pengujian homogenitas 
dilakukan untuk mengetahui apakah data penelitian memiliki varian yang homogen atau tidak. Dalam penelitian ini uji homogenitas dilakukan berdasarkan uji kesamaan varian kedua kelas, menggunakan uji Fisher pada taraf signifikasi $(\alpha)=0,05$ dengan kriteria pengujian yaitu, jika $F_{\text {hitung }}<F_{\text {tabel }}$ maka data kedua kelas mempunyai varian yang sama atau homogen.

Tabel 3. Hasil Uji Homogenitas Data PretestPosttest Kelas Eksperimen dan Kelas Kontrol

\begin{tabular}{cllll}
\hline \multirow{2}{*}{ Statistik } & \multicolumn{2}{l}{ Eksperimen } & Kontrol & \\
\cline { 2 - 5 } & Pretest & Posttest & Pretest & $\begin{array}{l}\text { Posttes } \\
t\end{array}$ \\
\hline$S^{2}$ & 229,09 & 92,26 & 238,83 & 194,79 \\
\hline$F_{\text {hitung }}$ & 0,41 & & 0,82 & \\
\hline$F_{\text {tabel }}$ & 1,84 & 1,84 & \\
\hline $\begin{array}{l}\text { Kesimp } \\
\text { ulan }\end{array}$ & Homogen & Homogen & \\
\hline
\end{tabular}

Berdasarkan tabel di atas, dapat disimpulkan bahwa data dari kedua kelas sampel tersebut mempunyai varian yang sama atau homogen

\section{Uji Hipotesis}

Setelah dilakukan uji prasyarat analisis data, diketahui bahwa data kedua kelas pada penelitian ini berdistribusi normal dan homogen, sehingga pengujian data kedua kelas dilanjutkan pada analisis data berikutnya yakni uji hipotesis menggunakan uji t.

Tabel 4 Group Statistic

\begin{tabular}{ccccc}
\hline Kelas & $\mathrm{N}$ & Mean & $\begin{array}{c}\text { Std. } \\
\text { Deviation }\end{array}$ & $\begin{array}{c}\text { Std. } \\
\text { Error } \\
\text { Mean }\end{array}$ \\
\hline $\begin{array}{c}\text { Eksperi } \\
\text { men }\end{array}$ & 37 & 73,73 & 9,605 & 1,579 \\
\hline Kontrol & 37 & 57,46 & 13,957 & 2,295 \\
\hline
\end{tabular}

Berdasarkan tabel di atas, diketahui jumlah data untuk masing-masing kelas adalah sebanyak 37 orang peserta didik. Nilai rata-rata atau mean untuk kelas eksperimen adalah sebesar 73.73, sedangkan untuk kelas kontrol sebesar 57.46. Dengan demikian secara deskriptif statistik dapat disimpulkan ada perbedaan rata-rata antara kelas eksperimen dan kelas kontrol. Selanjutnya untuk membuktikan perbedaan tersebut nyata atau tidak maka kita perlu menafsirkan tabel "Independent Samples Test" berikut ini.

Berdasarkan data yang diperoleh, diketahui bahwa nilai Sig. Levene's Test for Equality of Variances adalah $0.342>0.05$ maka dapat diartikan bahwa varians data antara kelas eksperimen dan kelas kontrol adalah homogen atau sama. Sehingga penafsiran tabel di atas berpedoman pada nilai yang terdapat dalam tabel "Equal Variances Assumed"

Pada bagian "Equal Variances Assumed" diketahui nilai Sig. (2-tailed) $<0.05$ maka sebagaimana dasar pengambilan keputusan dalam uji independent sample $t$ test dapat disimpulkan bahwa $H_{0}$ ditolak dan $H_{1}$ diterima. Dengan demikian penelitian ini dapat menguji kebenaran hipotesis bahwa terdapat perbedaan setelah diberikan perlakuan pada kelas eksperimen.

\section{SIMPULAN DAN SARAN}

\section{Simpulan}

Berdasarkan hasil penelitian dan pembahasan yang telah dikemukakan pada bab sebelumnya, dapat diketahui bahwa keterampilan berpikir kreatif peserta didik yang diajar menggunakan blended learning berbantuan google classroom lebih tinggi daripada yang diajar tanpa menggunakan blended learning berbantuan google classroom. Hal ini membuktikan bahwa terdapat perbedaan keterampilan berpikir kreatif peserta didik kelas X IPA di SMA Negeri 1 Campalagian antara yang diajar menggunakan blended learning berbantuan Google Classroom dan yang diajar tanpa menggunakan blended learning berbantuan Google Classroom pada materi hukum Newton.

\section{Saran}

Seiring dengan kemajuan teknologi saat ini, ada baiknya jika proses belajar mengajar melibatkan pemanfaatan teknologi didalamnya, sebab dengan teknologi guru dapat memberikan kemudahan dalam memaparkan materi ajar dan membuat kegiatan belajar mengajar lebih nyata. Diharapkan kepada guru mata pelajaran khususnya fisika, agar menggunakan model pembelajaran yang bervariasi, salah satunya 
dengan penggunaan blended learning yang dapat dikombinasikan dengan metode pembelajaran dan pendekatan yang sesuai. Kerjasama peserta didik dalam menyelesaikan tugas atau kerja kelompok harus ditingkatkan agar memperoleh hasil yang lebih baik. Hendaknya jadwal pelajaran fisika ditempatkan pada jam-jam awal pelajaran agar pembelajaran fisika lebih optimal.

\section{DAFTAR PUSTAKA}

[1] Sistem Pendidikan Nasional. (2003). UU RI No. 20 Th. 2003 tentang Sistem Pendidikan Nasional. Bandung: Fokus Media.

[2] [2] Nirfayanti, \& Nurbaeti. (2019). Pengaruh Media Pembelajaran Google Classroom Dalam Pembelajaran Analisis Real Terhadap Motivasi Belajar Mahasiswa. Jurnal Penelitian Matematika Dan Pendidikan Matematika, 2(1), 50-59.

[3] Aris (2020). Keefektifan Penggunaan Platform Google Classroom dan Schoology Terhadap Hasil Belajar siswa Pada Mata Pelajaran Dasar Desain Grafis Kelas X Multimedia SMK Negeri 1 Kebumen.

[4] Permata, A., dan Bhakti, Y.B. (2020). Keefektifan Virtual Class Dengan Google
Classroom Dalam Pembelajaran Fisika Di Masa Pandemi Covid-19. JIPFRI (Jurnal Inovasi Pendidikan Fisika dan riset Ilmiah), 4(1).

[5] Nukhbatul Bidayati, H., dkk. (2020). Pengaruh Blended Learning Berbantukan Google Classroom Terhadap Keterampilan Berpikir Kreatif Dan Kemandirian Belajar Peserta Didik. Jurnal Pendidikan Sains \& Matematika, 8(1).

[6] Sugiyono. (2013). Statistika untuk Penelitian. Bandung : Alfabeta

[7] Sugiyono. (2019). Metode Penelitian Pendidikan. Pendekatan Kuantitatif, Kualitatif, Kombinasi, R\&D dan Penelitian Pendidikan. Bandung : Alfabeta.

[8] Wahab, Abdul. (2013). Pengantar Statistika. Yogyakarta : Kutub Wacana. 